\title{
Utilization Patterns of Anti-Asthmatic Drugs Use in Albania During 2004-2014
}

\author{
PhD Laerta Kakariqi \\ Department of Biomedical and Experimental Subjects \\ Pharmacology Section, Faculty of Medicine, University of Medicine
}

\begin{abstract}
Aim: To evaluate the patterns of use of the out-of-hospital Anti-Asthmatic drugs in Albania during the period 2004-2014. Methods: The study was retrospective and we analyzed the prescription and consumption of these drug classes in the primary health care in Albania during 2004-2014. All data were collected from Health Insurance Institute (HII) ${ }^{[1]}$ and analysed reflecting the ambulatory and outpatient use for the period 2004-2014. The data about the consumption of drugs were expressed as a number of Defined Daily Dose (DDDs) /1000 inhabitants/day. Utilization was measured in DDD/1000 inhabitants/day and was also compared with Bronchial Asthma morbidity/1000 inhabitants, to understand the covering of the population from the reimbursement scheme. For all the period under study 2004-2014, there were collected and analysed the data of import and domestic production of drugs, which altogether represent the real consumption of drugs in the country. These data were subsequently included in a comparative analysis with the utilization data according to the HII. Results: The values of consumption of Anti-Asthmatic drugs were 6.62-8.48 DDD/1000 inhabitants/day respectively in 2004-2014. 2.14-3.76 DDD/1000 inhabitants/day constitute the consumption of beta2 agonists and 2.66-3.69 DDD/1000 inhabitants/day is the consumption of corticosteroids. In addition, it turns out that the consumption of beclometasone and the association Beta-2-mimetic-corticosteroids (salmeterol+fluticasone) based on HII data is superior to the consumption of this forms based on Import data, which cannot be true. This finding probably reflects fictive prescriptions and the entry of drugs by contraband. During some years of our study we notice that the consumption of Antiasthmatic drugs is higher than the morbidity level (cases/1000 inhabitants). Conclusions There is only a small increase in the national consumption of Anti-Asthmatic drugs during these years, but the values still remain very low in comparison with other countries. Less than $40 \%$ of the consumption of beta2 agonists is covered from the reimbursement scheme. In addition, it results that the scheme covers about $50 \%$ of antiasthmatic drugs consumption.
\end{abstract}

Keywords: Drug utilization, DDD, Anti-Asthmatic drugs, bronchial asthma

\section{Introduction}

Between 100 and 150 million people around the globe suffer from asthma and this number is rising. World-wide, deaths from this condition have reached over 180,000 annually [2]. Asthma is not just a public health problem for developed countries. In developing countries, however, the incidence of the disease varies greatly. Mortality due to asthma is not comparable in size to the day-to-day effects of the disease. Although largely avoidable, asthma tends to occur in epidemics and affects young people. The human and economic burden associated with this condition is severe. The costs of asthma to society could be reduced to a large extent through concerted international and national action. WHO recognizes asthma as a disease of major public health importance and plays a unique role in the co-ordination of international efforts against the disease. ${ }^{[2]}$

According to the detailed data deriving from physicians, in year 1997, in Albania, only $3 \%$ of the population resulted as affected from asthma. This figure today has reached $13 \%$. Such difference indicated that the disease has returned and is being spread quickly, a situation that requires immediate intervention. The pediatric age is most at risk and more and more affected by asthma -1 in every 4 children suffers from bronchial asthma ${ }^{[3]}$.

Based on studies performed in Albania as part of international studies (ECHRS, ISAAC), the prevalence of asthma for the age of $13-14$ years old has resulted $2.6 \%$ in 1995 and has reached $3.4 \%$ in 2000. The study for year 2011, whose data are 
currently being elaborated, is expected to present a further increase in the prevalence, provided that Albania has now adopted a western method of living [3].

The morbidity data referred from HII indicates that the number of Asthmatic patients in Albania (expressed in cases/1000 inhabitants) is 5.26-8.09 cases/1000 inhabitants, 2004-2014.

Although Bronchial Asthma cannot heal it can be cured and controlled.

Because asthma is a chronic condition, it usually requires continuous medical care.

The treatment is a major issue, especially in developing countries as Albania, where the high cost of medicine constraints patients to not obtain the treatment. A long and serious follow-up of asthma would enable patients to reach a good level of control over their disease.

\section{Objective, Materials and Methods}

\subsection{Objective:}

To evaluate the out-of-hospital Anti-Asthmatic drugs use in Albania during the period 2004-2014.

\subsection{Materials and Methods:}

The data were obtained from the HII. These data were collected and analysed for all the period 2004-2014.

The data included the total number quantities of drugs used from the prescriptions.

The population data were obtained from the Institute of Statistics (INSTAT) ${ }^{[4]}$. The consumption of drugs was expressed as a number of Defined Daily Dose (DDDs)/1000 inhabitants/day. All drugs were classified by groups of Anatomic Therapeutic Chemical Classification (ATC).

Data on the levels of Bronchial Asthma morbidity

From the database of HII we extracted the general number of patients reported with this diagnose, for each year. In addition, we calculated the respective levels of annual morbidity (based on the respective code-diagnoses) for 1000 inhabitants.

The total number of Asthmatic patients reported from the HII data base is shown in the table below:

\begin{tabular}{|l|l|}
\hline Years & Number of Asthmatic patients \\
\hline 2004 & 16,597 \\
\hline 2005 & 19,837 \\
\hline 2006 & 17,572 \\
\hline 2007 & 17,010 \\
\hline 2008 & 17,795 \\
\hline 2009 & 18,301 \\
\hline 2010 & 22,636 \\
\hline 2011 & 23,565 \\
\hline 2012 & 24,910 \\
\hline 2013 & 25,798 \\
\hline 2014 & 26,936 \\
\hline
\end{tabular}

Table1 Total number of Asthmatic patients reported from HII in each year of the study period

Data on real consumption (import and domestic production)

For all the period under study 2004-2011 there were collected and analysed data from the import and domestic production of the drugs ${ }^{[5]}$ which represent the real consumption of drugs in the country. It was noted that the increase in consumption from one year to another was small, e.g. the consumption from 2011 to 2014 (i.e. 4 years) was increased by only 1.97\%. Consequently, in order to obtain an updated study, there were chosen the data of import and domestic consumption only for the last three years, 2012, 2013, 2014, and those were included in a comparative analysis with the equivalent consumption data according to HII. In order to minimize the effect of variations between consumption and stock inventory 
balances from one year to another, it was calculated and put to analysis the annual average value of the three chosen years (on one hand that of the import and domestic consumption, and on the other hand that of HII).

Presentation of the results and statistical elaboration

The database of HII was modified in Microsoft Office Excel 2007, whereas the statistical elaboration of the obtained results was conducted with the statistical package StatsDirect (version 2.7.2.). A descriptive statistics was used to report all data on drugs consumption and the results obtained were displayed in tabular form as well as through the histogram method.

Average annual values of consumption in the country level and for each district were used as a basis to generate the overviews and the graphics that illustrate the trends of consumption for each class of drugs during the 10-years period 2004-2014. The linear regression model was used to evaluate the trends of consumption of drugs relative to the time. A value of $p \leq 0.05$ was considered as significant.

In order to asses if there exists a correlation statistically significant between the level of consumption of drugs and the level of morbidity, it was applied the Spearman correlation (with a significance level of $\leq 0.05$ ).

\section{Results}

The data were expressed as a number of defined daily doses per 1000 inhabitants/day (DDDs/1000 inhabitants/day).

Drugs included in the reimbursment list are: aminophylline, beclomethasone, budesonide, fluticasone, formoterol, ipratropium, salbutamol, salmeterol, salmeterol+fluticasone, theophylline.

The consumtion of AntiAsthmatic drugs results 6,62-8.48 DDD/1000 inhabitants/day (2004-2014). In addition the consumtion of Beta2 agonists is 2,14-3.76 DDD/1000 inhabitants/day (2004-2014); corticosteroids: 2,66 -3.69 DDD/1000 inhabitants/day (2004-2014); methylxanthines: 1,74 - 1,33 DDD/1000 inhabitants/day (2004-2014).

Asthmatic morbidity data indicate that there does not exist a correlation statistically significant between this disease and the trend of consumption of Anti-Asthmatic drugs, $(p=0,6615)$, (Figure 1).

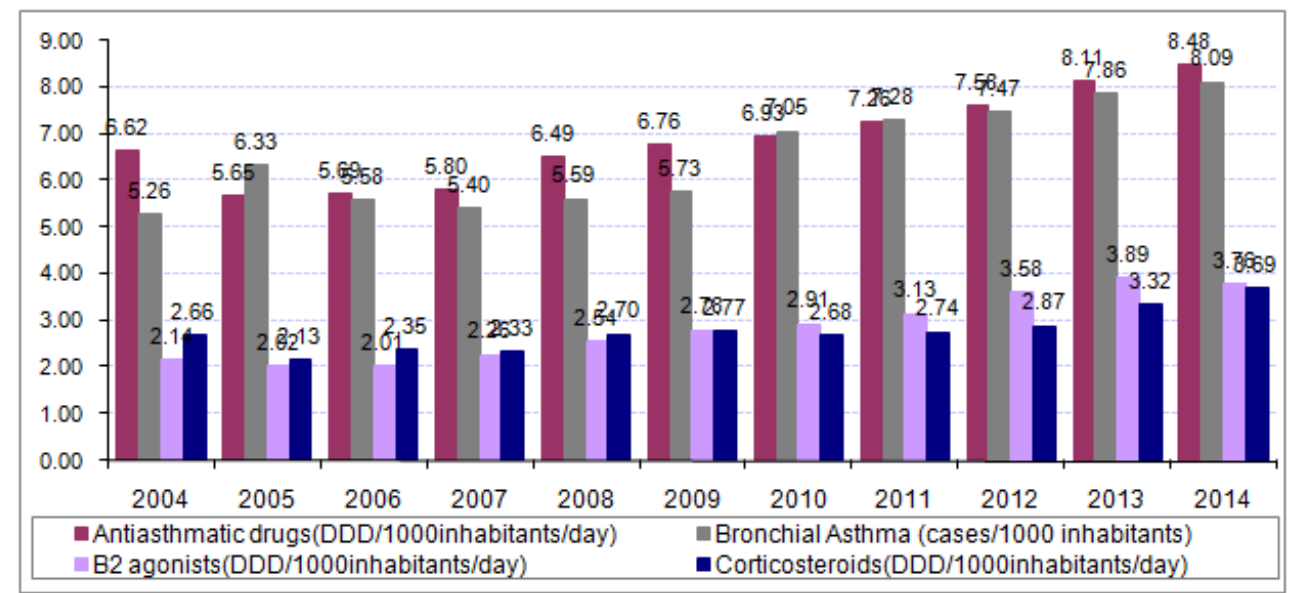

Figure 1Consumption of Anti-Asthmatic drugs at the national level (DDD/1000 inhabitants/day) versus Bronchial Asthma morbidity (cases/1000 inhabitants); $(p=0,1928$; strength (with significance level $\leq 0,05)=24,4 \%$; correlation coeficient is not statistically significant).

The annual average value of drugs used for Asthma disease and the annual average value of consumption of each alternative, as a consumption from import (real actual consumption) versus the consumption reported by HII (DDD/ 1000 inhabitants/day), (2004-2014), are respectively presented in Figures 2 and 3. 


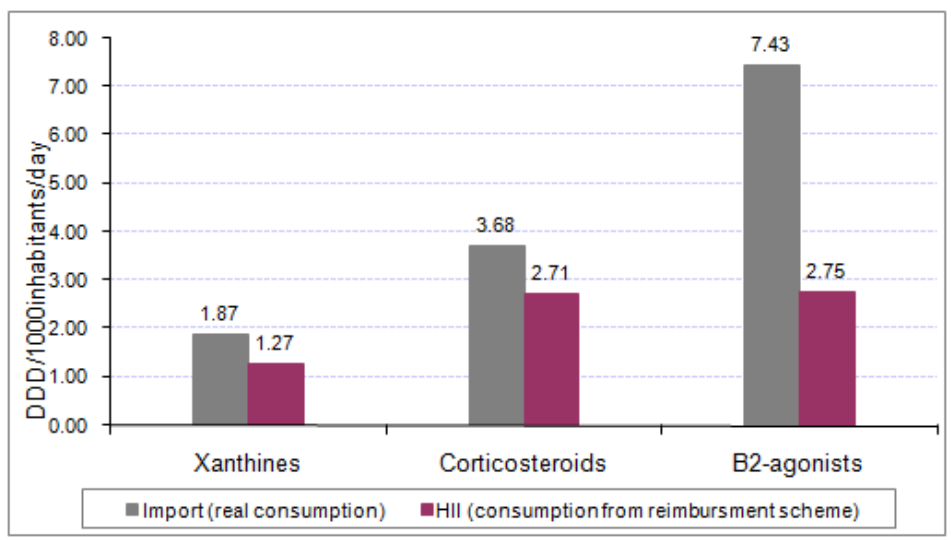

Figure 2 Annual average value of consumption of drugs used for Bronchial Asthma: consumption based on import (real consumption) [*] versus consumption based on HII.

["] The "Import" item includes the consumption based on import data as well as the consumption based on domestic production: this represents the factual consumption.

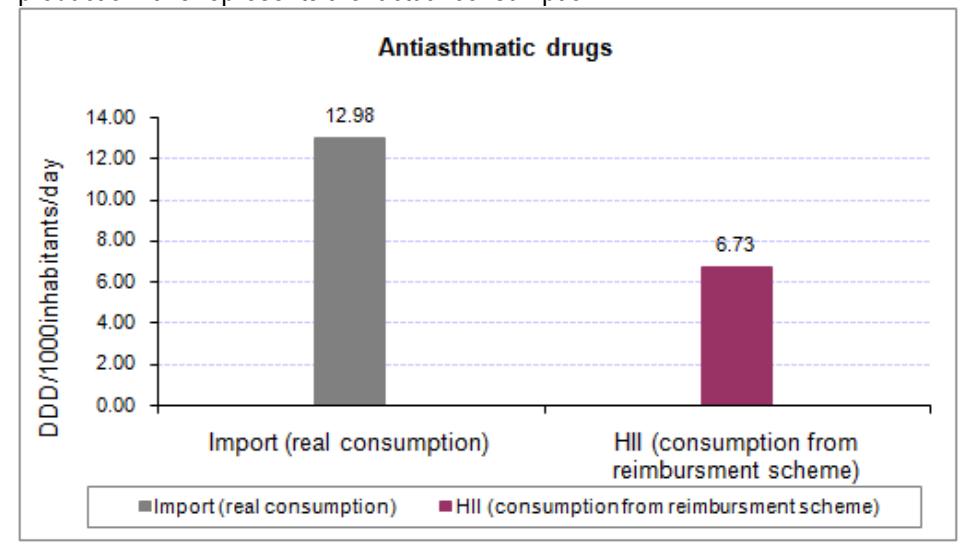

Figure 3 Annual average value of consumption of drugs used for Bronchial Asthma in total: consumption based on import (real consumption) versus consumption based on HII (DDD/1000 inhabitants/day).

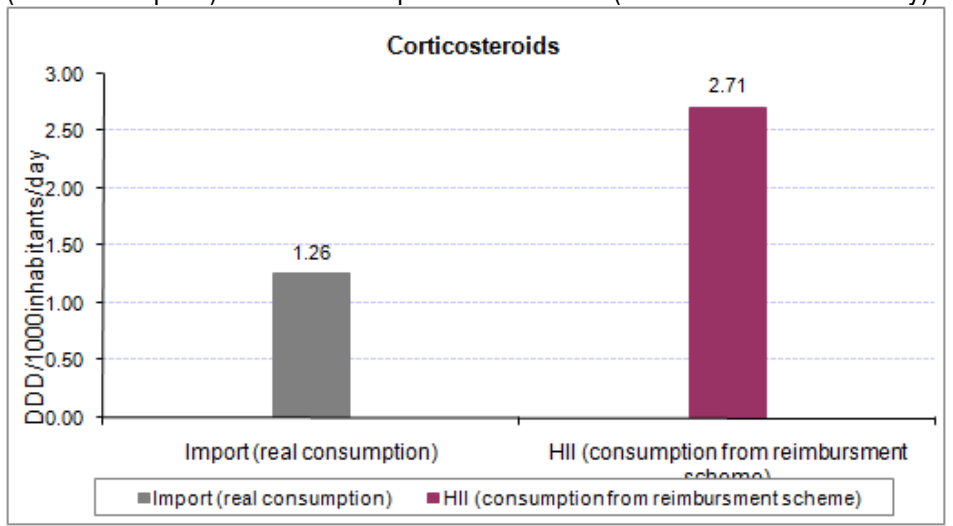

Figure 4 Annual average value of consumption of Corticosteroids: consumption based on import (real consumption) versus consumption based on HII (DDD/1000 inhabitants/day). 


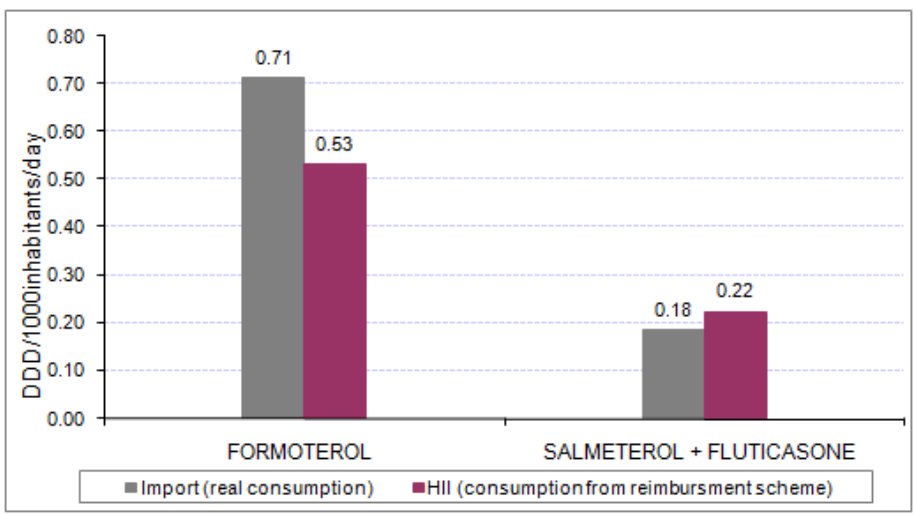

Figure 5 Annual average value of consumption of Beta2 agonists inhalators : consumption based on import (real consumption) versus consumption based on HII (DDD/1000 inhabitants/day).

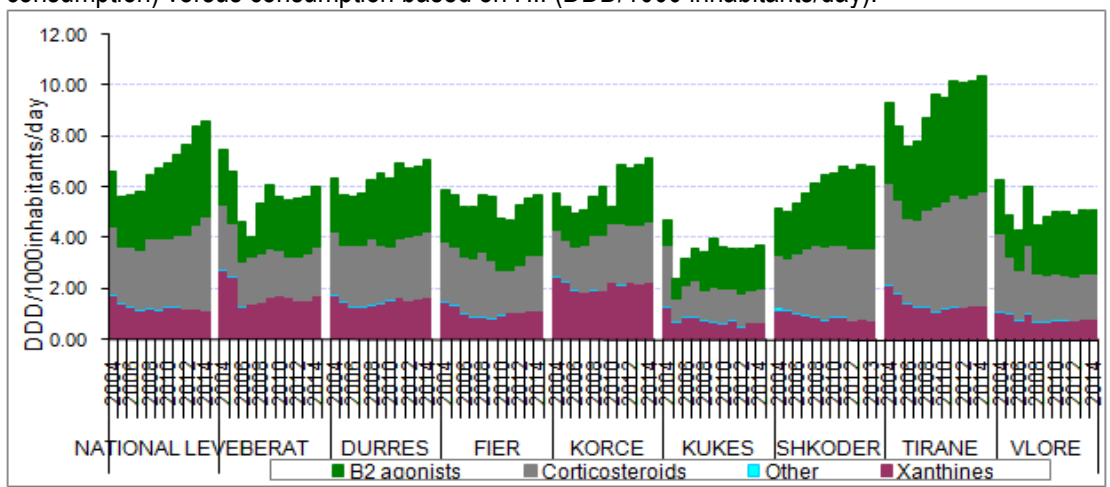

Figure 6 Consumption of drugs used for Bronchial Asthma in different regions and at the national level (DDD/1000 inhabitants/day).

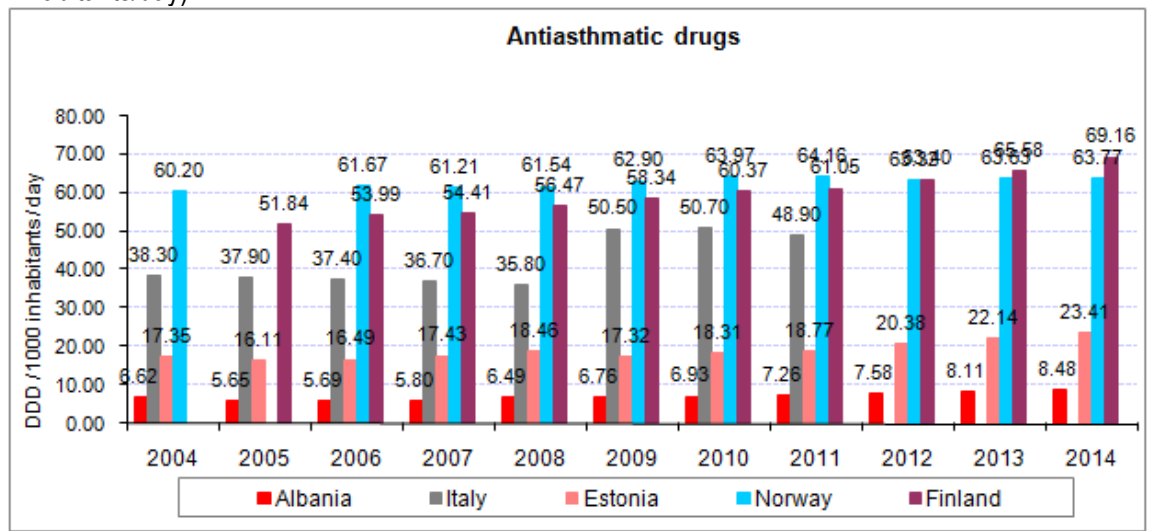

Figure 7 International comparisons of Anti-Asthmatic drugs consumption. Norway [6,7], Estonia [8, 9], Finland[10,11], Italy [12,13,14], (DDD/1000 inhabitants/day)

\section{Discussion}

Bronchial asthma consists in the main obstructive pulmonary disorder in young and medium ages (less than 50 years old). In elder ages, bronchial asthma is often accompanied by chronic obstructive pulmonary disease (COPD), leading to difficulties in determining the correct diagnosis ${ }^{[15,16]}$. 
In Figure 1 it is noticeable that the consumption of anti-asthmatic drugs in most of the years exceeds the figures of asthmatic morbidity. This trend can be explained by the fact that these drugs are reimbursable not only for bronchial asthma, but also for the treatment of COPD level III, IV, as well as for the treatment of chronic bronchitis with or without emphysema. In the meantime, there can be noted a regular and almost parallel consumption of $b_{2}$ agonists and corticosteroids - $a$ fact that indicated their joint usage but in separate formulations.

In order to understand better the real situation, we analysed the data of consumption connected with imports. The comparison between the average annual consumption value connected with imports and the corresponding value obtained from HII is presented in Figure 2, where it can be noted again that the imports exceed the consumption reported by HII. Less than $40 \%$ of the consumption of b2 agonists is covered by scheme, whereas corticosteroids are consumed within the scheme at a level of around $70 \%$. Figure 3 shows that HII covers only around $50 \%$ of the consumption of anti-asthmatic drugs.

The question we pose is: what did really happen and which were the reasons? In the case of consumption reported by HII for this class of drugs, it appears for the first time that the consumption covers relatively well the reported morbidity, by even exceeding it in a few years. On the other hand, from the analysis of the real consumption data (connected with imports) it results that scheme covers only around $50 \%$ of the consumption of anti-asthmatics, the rest flows outside of it.

We analyse below each of the major anti-asthmatic groups.

Xanthines derive from the scheme at around $70 \%$, the rest flows outside of it. A possible reason can be that fact that they have a low price and a part of patients prefer to get them directly in pharmacies, by skipping/avoiding the general physician step.

The consumption of corticosteroids characterised by two features that need the respective clarification. More specifically, the total import exceeds the consumption as reported by HII, whereby an important role is played by alternatives outside of the scheme that circulate in the pharmaceutical market such as: the combination beclomethasone+salbutamol, mometasone, flunisolid.

Whereas, if we compare only the corticosteroids included in the scheme (beclomethasone, budesonide, fluticasone) with the analogue values related to imports, the result appears as reversed: HIl exceeds more than twice the total consumption based on import (Figure 4). This abnormal situation can be due to fictitious drug prescriptions. The reason for such abusive prescriptions is somehow related to the high costs and the deemed high profits involved with these drugs.

We have found a similar situation in more occasions throughout our studies, where there resulted higher consumption values reported from HII compared to import values but we would have expected instead that import values had included the primary health care consumption values. This anomaly is particularly noted in expensive drugs with a continuous chronic consumption, as is the case of anti-asthmatics (mainly inhaled combinations of corticosteroids and beta2 agonists) (Figure 8)

Another reason for this situation can also be the entry of drugs without customs clearance (contraband).

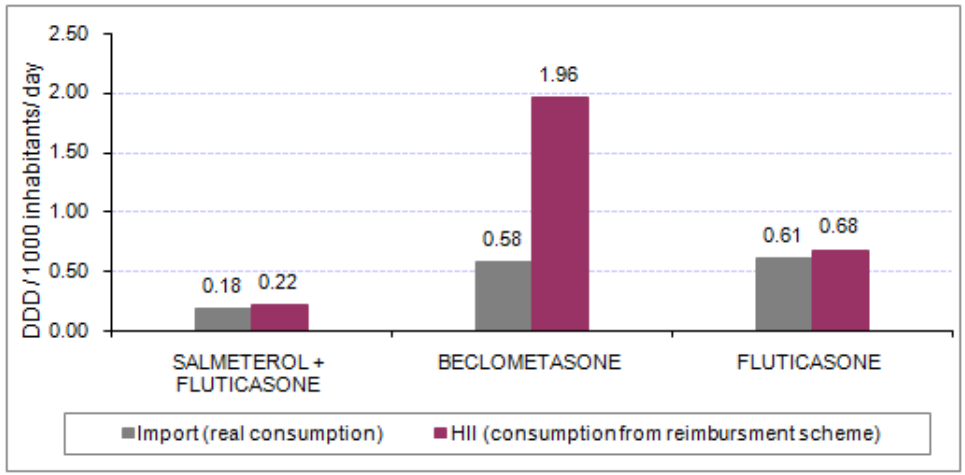


Figure 8 Annual average value of consumption of inhaled corticosteroids and there combinations with long acting Beta2-agonist inhalators: consumption based on import (real consumption) versus consumption based on HII (DDD/1000 inhabitants/day).

The consumption of $b_{2}$ agonists is also characterized by anomalies of both types. In total, the consumption based on imports exceeds few times the consumption within the scheme and the main consumed item is salbutamol oral tablet, for which, as for xanthines, the reimbursement scheme is overlooked in the majority of cases. Whereas, for inhaled beta2 agonists which similarly to inhaled corticosteroids and combined fix formulations have high costs, the situation appears different. In Figure 5 there can be again noted the anomaly of excess of consumption according to HIl versus import. Probably, this illustrates again the effect of fictitious and abusive prescriptions.

The consumption of this class in some regions (Figure 6) results to be decreasing, whereas in principle, there can be expected an increasing trend. The region with the lowest consumption values for anti-asthmatic drugs is Kukës, with decrease from 2004 to 2014 and with the minimum consumption values registered in 2005: twice as low as in 2004. Other regions with low consumption values are Fieri, Vlora, Berati, where there is again noted a considerable decrease of consumption from year to year (2004-2014). It is difficult to explain this phenomenon, considering the chronicity of the pathology and its natural increase. Morbidity data show its growth to be at the level of $42.83 \%$ (from 5,26 cases/1000 inhabitants in 2004 to 8.09 cases/1000 inhabitants in 2014).

The region with the highest consumption values is Tirana, characterised by consumption stability: 9,31-10.38 DDD/1000 inhabitants/day, 2004-2014. The same stable consumption is noted also in Durrës: 6,36-7.08 DDD/1000 inhabitants/day, 2004-2014.

At the national level, the consumption of this group remains relatively constant and in low values. There can be noted a decrease of consumption in 2005-2006 and then a gradual increase in subsequent years.

Following the results of TORCH study, international therapeutic guides are increasingly turning into a therapeutic standard the pre-prepared associations of long-acting beta2 agonists and inhaled corticosteroids for all obstructive chronic bronchial

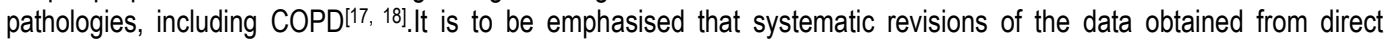
comparisons of an-associated consumption (sole usage) of long-acting beta2 agonists, do not bring to evidence clinical benefits, on the contrary, they indicate a significant increase of side effects, especially of pneumonia ${ }^{[19,20]}$. Based on insurance data, obtained from a meta-analysis with over 60.000 patients, FDA has recently released a series of communications on the correct usage of long-acting beta2 agonists in asthmatic patients, which has led to modification of the drug leaflet-guide. Especially in the treatment of bronchial asthma, the usage of beta2 agonists not associated with steroids is strongly counter-indicated due to the added risk of appearance of severe episodes of acute asthma (need to hospitalize, need of intubation, and even cases of death) ${ }^{[19,20]}$.

In our country, short-acting beta2 agonists continue to have high consumption values compared to long-acting beta agonists, a fact that indicates a poor control of bronchial asthma. According to the guidelines short-acting bet2 agonists should be used for short-term symptom relief. All other countries show a trend of significant increase (since the beginning of years ' 00 ) of consumption of long-acting beta2 agonists and especially of pre-prepared combinations with inhalation steroids, a trend that goes in line with international therapeutic guides.

\section{International consumptions comparisons}

The consumption of anti-asthmatic drugs in Albania, in total, is multiple times lower compared to other countries (Figure 7).

In European countries, the main item in the consumption of anti-asthmatics is beta2agonists (R03A)andespecially the associationsbeta2 agonists+corticosteroids (R03AK) $[6,7,8,9,10,11,12,13,14]$. The figure below (Figure 9) shows clearly the difference in consumption of this subclass in our country as compared to other European countries. 


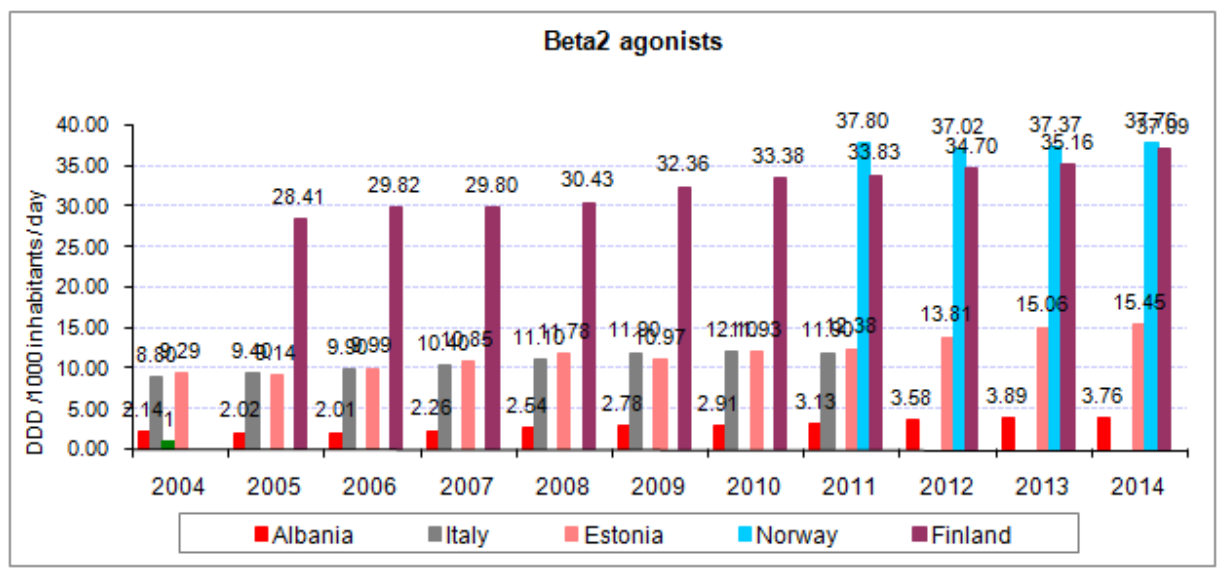

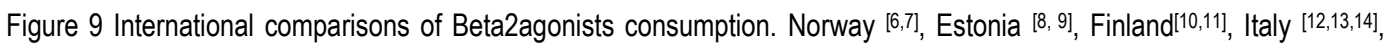
(DDD/1000 inhabitants/day)

\section{Conclusions}

The consumption of anti-asthmatic drugs has increased during 2004-2014.

In total, the consumption of anti-asthmatic drugs in Albania, is multiple times lower compared to other countries

We need to undertake other studies to deeply understand the reasons and the differences of the prescription and consumption of Antiasthmatic drugs in our country.

\section{References}

[1] 1.Health Insurance Institute; Ministry of Health;

[2] 2. World Health Organization (WHO), 2016

[3] 3. Ministry of Health, University Hospital Center Mother Teresa, Tirana, Albania, 2015

[4] 4. Institute of Statistics; INSTAT Albania

[5] 5. General Customs Directorate, Ministry of Finance, Albania

[6] 6.Norwegian Institute of Public Health. Drug Consumption in Norway 2006-2010. Department of pharmacoepidemiology, Norwegian Institute of Public Health; http://www.legemiddelforbruk.no.

[7] 7. Drug Consumption in Norway 2011-2015; ISSN:1890-9647 ISBN:978-82-8082-715-9 electronic version

[8] 8.Estonian Statistics on Medicines 2006-2010. Ravimiamet State Agency of MedicinesCopyright: Ravimiamet, 2010; ISSN 1736-5813

[9] 9. Statistical Yearbook of the State Agency of medicines 2015, ISSN 2228-2300

[10] 10.Finnish Statistics on Medicines 2007. National Agency for Medicines, Department of safety and drug information; ISSN 0786-2180

[11] 11. Finnish Statistics on Medicines 2014. National Agency for Medicines, Department of safety and drug information; ISSN 0786-2180

[12] 12. Gruppo di lavoro OsMed. L'uso dei farmaci in Italia. Rapporto nazionale anno 2007. Roma: II Pensiero Scientifico Editore, giugno 2008. 
[13] 13. Gruppo di lavoro OsMed. L'uso dei farmaci in Italia. Rapporto nazionale anno 2008. Roma: II Pensiero Scientifico Editore, giugno 2009.

[14] 14. Gruppo di lavoro OsMed. L'uso dei farmaci in Italia. Rapporto nazionale anno 2009. Roma: II Pensiero Scientifico Editore, 2011.

[15] 15. Lundback B, Gulsvik A, Albers M, et al. Epimediological aspects and early detection of chronic obstructive airway diseases in the elderly. Eur Respir J 2005; 21(Suppl. 40): 3s-9s.

[16] 16. Lindstrom M, Jonsson E, Larsson K, Lundback B. Underdiagnosing of obstructive lung disease in northern Sweden. Int J Tuber Lung Dis 2002; 6:78-84.

[17] 17. Calverley PM, Anderson JA, Celli B, et al. Salmeterol and Fluticasone Propionate and Survival in COPD. N Engl J Med 2007; 356:775-789.

[18] 18. Nannini LJ, Cates CJ, Lasserson TJ, et al. Combined corticosteroid and long-acting beta-agonist in one inhaler versus long acting beta-agonists for chronic obstructive pulmonary disease. Cochrane Database of Systematic Reviews 2007, Issue 4. Art. No. CD006829.

[19] 19. Rodrigo CJ, Casto-Rodriguez JA, Plaza V. Safety and Efficacy of Combined Long-Acting b2 agonists and Inhaled Corticosteroids vs Long-Acting b2 agonists Monotherapy for Stable COPD: A Systematic Review. Chest 2009; 136:1029-1038.

[20] 20.http://www.fda.gov/Drugs/DrugSafety/PostmarketDrugSafetylnformationforPatientsandProviders/ucm20077 6.htm (2010) 